\title{
Blood Bilirubin Increased, CTCAE
}

National Cancer Institute

\section{Source}

National Cancer Institute. Blood Bilirubin Increased, CTCAE. NCI Thesaurus. Code

C143325.

A finding based on laboratory test results that indicate an abnormally high level of bilirubin in the blood. Excess bilirubin is associated with jaundice. 